\title{
The Integration of Early Childhood Systems within Education ${ }^{i}$
}

\author{
John Bennett
}

Yoshie Kaga

UNESCO

\begin{abstract}
The rationale for this study sprang from the dissatisfaction expressed in many countries during the OECD reviews about the split in services. Because of the split, ministries had ceased to talk with each other: early education had tended to become a junior school and care a question of baby-sitting while mothers worked. In particular, the low qualifications of staff in child care and the suppression of children's natural learning strategies in kindergarten had become matters of concern. Examples of integrated systems were already available in the Nordic countries to show that such oppositions were not necessary. The integration of early education and childcare is often considered a question of auspices or administration. To the contrary, our analysis shows that to be successful, integrations must go deeper than this. As examples, integration is examined in some countries, in particular, in the forerunners, such as New Zealand and Sweden, and then in some of the newcomers, such as Brazil and Slovenia. Finally, conclusions and recommendations are provided.
\end{abstract}

Key words: integration of early education and care, early childhood systems

\section{An overview of the study}

\section{The complexity of early childhood systems}

Early childhood care and education (ECCE) is a complex policy area. It is concerned not only with

Correspondence concerning this article should be addressed to John Bennett, Senior Consultant to UNESCO, and Yoshie Kaga, Programme specialist, Early childhood care and education at the Division of Basic Education, UNESCO Headquarters, 7 Place de Fontenoy 75007 Paris, France. Electronic mail may be sent to bennett. paris@gmail.com and Y.kaga@unesco.org. In the original research, a leading role was played by Professor Peter Moss of the Thomas Coram Research Unit, Institute of Education, London childcare and early education, but also with child health and nutrition, social welfare and protection, women's employment and equal opportunities, poverty issues and readiness for school. Given its

multi-sectoral nature, all countries face difficulties in achieving coordinated approaches to early childhood services. In many developing countries, the difficulties are primarily financial, but in countries such as Brazil and Jamaica - as well as in the OECD countries in our study - the different histories of care and education also add to the challenge of coherence.

\section{Two different histories in centre-based care and education}

Early childhood care and education embodies two different traditions: care and education. The former 
emerged as charitable activities or as health or welfare centres for the children of working parents or from families at-risk. These centres addressed particularly the health of poor mothers and infants, as in the late 19th century, infant and child mortality was extremely high. A high moralisation of motherhood took place and great emphasis was placed on health and hygiene. In contrast, kindergartens and pre-primary classes were generally created by the middle-classes to prepare young children for primary schooling. Given their distinct historical roots, 'childcare' and 'early education' services embody different visions of young children and childhood. These understandings are embodied in different programme goals, contents and approaches, often inconsistent with one another.

Today, these traditions are expressed in most countries as 'split systems' of ECCE. Typically, care and education are separated and are governed, in terms of policy making and administration, by health/social welfare and education ministries respectively. They are also structured in very different ways with respect to types of service, workforce, access criteria, funding and regulation (including curriculum).

\section{Disadvantages of split systems}

Split systems have been the subject of critical discussion since the 1970s, and analyses have identified several core problems. For example, education is considered to begin when children are aged 3 or 4, with younger children defined as needing only minding or care while their parents work. Problems associated with split systems have been documented to some extent: e.g. inefficiency due to duplication and wastage of resources as well as competition and conflicts among the concerned ministries; funding streams and monitoring mechanism; disparities in access and quality due to the differences in entitlement policies, opening hours, regulatory frameworks, staff training and qualification requirements; failure to take a holistic approach to children's needs; and discontinuities experienced by children transiting from one service to another.

\section{Responses to split system inefficiencies}

One response to these problems is to create interministerial mechanisms to promote more coordinated approaches to ECCE provision. Evidence suggests that coordination mechanisms can work well to accomplish a specific mission or to focus on a targeted population, but are not successful in promoting a coherent overall policy and administrative framework across sectors.

Another, more integrative response is consolidating national responsibility for ECCE into a single ministry. If one excepts the Russian experiment of 1917, the Nordic countries pioneered this policy approach in the 1960s and 70s, bringing together national responsibility for ECCE within social welfare. Since the late 1980s, the trend has been toward integration of ECCE within education: e.g. Iceland, New Zealand (1986), Vietnam (1986), Spain (1990), Botswana (1994), Brazil (1996), Slovenia (1996), Sweden (1996), England (1998), Jamaica (1998), Scotland (1998), Norway (2005), Romania (2008), Zambia (2004), and Ontario (Canada) (2010).

\section{Reasons for the choice of education}

Locating the responsibility for ECCE within education is important as the education framework highlights access, affordability, concern for a (relatively) well trained workforce, and curriculum as a basic tool for practice. In addition, education stresses the importance of lifelong learning and a recognition that children are learners from birth. Education ministries have naturally a greater concern for laying a strong foundation for successful schooling. There is also the view that the infrastructure within the education sector is more transparent and, compared to the social sector, provides an easily recognisable network of services for young children that is often based on a universal entitlement. The risks associated with integration within education are: turning ECCE 
services more 'school-like' in terms of opening hours, staffing, adult-child ratios, pedagogy and physical settings; and the dissociation of ECCE from welfare, health and other related areas.ii

\section{Rationale for the study}

The main rationale for the study is that up-to-date and comprehensive research evidence allowing a thorough assessment of the policy option is lacking. Studies and reports published by UNESCO - such as the EFA Global Monitoring Report 2007: Strong Foundations - and the two OECD Starting Strong reports provide some knowledge about systemic and integrated approaches to ECCE. But they include only certain country cases or do not provide substantive and updated accounts of the reform implementation, and thus offer only a partial picture of the moving of ECCE services into the education system.

The Caring and Learning Together project, sponsored by UNESCO, addresses this knowledge gap. It focuses on 'integration within education' as a particular policy approach in order to bring greater coherency into ECCE services, to improve quality and upgrade the status of staff in the sector. It also has sought to contribute to a better understanding of this policy option by looking at selected countries that have made this move. Specifically, it explores the rationales, aims, processes, progress and consequences of this approach.

\section{Research objectivity}

The project also recognises and appreciates other policy options for achieving more coordinated approaches, e.g. the better outreach of health systems to families. It offers a critical perspective on how education has handled the pre-school education of young children in some countries, and seeks to provide a better understanding of the perspectives of countries that have not adopted the option. For this reason, the study includes a country (Finland) that has integrated childcare and early education very successfully within social welfare. It also includes three countries or regions that have chosen to continue with split systems (Belgium Flanders, France, Hungary), in order to provide a better understanding of the case for not adopting integration-withineducation.

\section{Main focus of the study}

The main focus of the study is an evaluation of the experience of several countries that have made the move to education. As such, it draws on the experiences of Brazil, Jamaica, New Zealand, Slovenia, Sweden and the city of Ghent (in the Flemishspeaking Community of Belgium) in opting for integration-within-education; and on those of the Flemish-speaking Community of Belgium, France, Finland and Hungary which take a different approach to governance, namely either integration of ECCE within social welfare (in the case of Finland) or multiple-agency arrangements (in the case of Belgium Flanders, France and Hungary). The main report of the study (UNESCO, 2010) presents a synthesis of the historical contexts, rationales, processes and consequences of integrating ECCE within education, the views of the countries that apportion ECCE responsibility differently, and some reflections and policy recommendations on the issue.

\section{Limitations of the study}

Assessments drawn on for this study are partial due to an absence of comprehensive, long-term national evaluations of system change; a lack of opportunity to combine national and municipal reports iii with site visits; an absence of very low income countries among the cases studies; and the impossibility of knowing what would have happened if reform had not taken place. The reports also cover countries with varying contexts, therefore, evidence needs careful interpretation in reference to this contextual variation. Again, there are no inevitable consequences of moving responsibility for ECCE into education; what matters is why integration has been undertaken and how it is implemented. 


\section{A closer look at the countries under review}

\section{When and how did the transfer take place}

The historical process of transferring responsibility for ECCE to education has varied considerably among the five case countries studied. Sweden and Slovenia already had a wholly or partially integrated system before the transfer to education in 1996 and 1992 respectively. In New Zealand, Brazil and Jamaica, integration and transfer to education took place in 1986, 1996 and 1998 respectively, and were part of the same process. In all cases, the transfer has been based on a consensus, at least among experts, that care and education are inseparable; in two cases the process involved a wider campaign involving diverse groups in civil society. The rationale for change varies between countries but in all cases it has been strong and principled, rather than a purely pragmatic concern, for example, to cut costs or boost school readiness.

\section{The extent of integration}

It is useful to think of integration as having two aspects: conceptual integration (i.e. how do we think about integration), and structural integration (i.e. how do we organise ECCE). The former refers to the extent to which the ECCE system shares an understanding of what it is for and what it is doing, and how far integration is expressed in a common language. In other words, conceptual integration is achieved when the system has gone beyond thinking and talking about 'childcare' and 'education'. As for the latter, there are six areas of structural integration: (1) policy making and administration, (2) access to services, (3) funding, (4) regulation, including curriculum or similar guidelines, (5) workforce, including structure, education and pay, and (6) type of provision.

The extent of integration - how far the process has gone beyond transferring government responsibility for ECCE into education - varies considerably across the countries: it has gone furthest and deepest in Sweden and Slovenia. In Sweden for example, not only has integration taken place at administrative level but more importantly, it has evolved into the integration of the workforce, of financing, of regulation, organisation and structuring at local level, of national and municipal inspection (but with inspection teams fit-for-purpose). In addition, curricula are linked and a broad consensus has formed around 'Norms and Values', which emphasise care and consideration towards others, solidarity, gender equality and tolerance (Dahlberg \& Lenz Taguchi, 1994).

In their integration efforts, Brazil and Jamaica face the biggest challenges, as they have begun their reform only within the last few years, with deeply split systems and significantly fewer resources than the other richer countries; nevertheless they have made progress by undertaking curricular and regulatory integration and by upgrading the workforce (Jones, et. al., in press; Recende Nunes, et al., in press). Except in one case country, there is no evidence that integration within education has brought about 'schoolification' of ECCE services. .v $^{\text {iv }}$

The experience of Ghent, Belgium Flanders, demonstrates the possibilities and limitations of reform at local level. Ghent has brought ECCE services into one administration and promoted a common pedagogical approach across all municipal early childhood services. However, it has not been able to bring about other structural changes due to the municipality's limited competence. Finland, which has a welfare-based system, is a highly successful integrated system and points to the possibility of a non-education option, though this may be more feasible in Nordic welfare states.

\section{Lessons from countries that have integrated within education}

\section{Mostly, a very positive experience}

The consequences of integration within education have been positive, particularly for children under 3 
years and for services and staff that cater for this youngest group. In other respects such as curriculum development or pedagogical work, results have also been very positive, for example, in New Zealand, the link with education has inspired the creation of the Te Whariki curriculum and a specific learning evaluation instrument: 'Learning Stories' (Carr, 2001). The New Zealand Report states: 'If there had not been prior integration of services under Education, it is unlikely that New Zealand would have had a curriculum as innovative and as widely inclusive of early childhood education services as Te Whariki ...If childcare services had not been under the Ministry of Education, the curriculum probably would not have applied to them'. Perhaps even more striking have been the workforce changes that have taken place in New Zealand (Meade \& Podmore, 2002): higher qualifications for ECEC staff and improvements in pay supported by the creation in 1994 of a combined union for early childhood and primary school teachers. Since integration within education, 'there has been continued growth in the number of students in, and graduates from, early childhood teacher education colleges' (Meade \& Podmore, 2002).

Four of the five countries now have curricula covering children under and over 3 years - a clear consequence of integration within education. The fifth country, Jamaica, is aligning its separate curricula for under and over 3 years. Four of the five countries also have an integrated early years profession, a graduate level worker educated to work with both under and over 3 years olds. Jamaica, the fifth country, retains a split workforce, with a separate and higher status group working with older children, though some improvements are being made in the training of workers in 'day care' centres (Jones, et. al., in press). The same split remains in Ghent, which as a municipality does not have responsibility for the ECCE workforce, though integration into education has led to improved conditions for workers in municipal 'day care' centres.
On the other hand, there was little evidence of one potential benefit of integration, that is the ECCE system having influence on the school system through the development of what the OECD Starting Strong review has termed 'a strong and equal partnership'.

\section{Above all, access has improved}

Access to services has increased in all cases, though by very varying amounts, and it is not always possible to decide how much is accounted for by the reform process. However, in Sweden and Slovenia, a universal entitlement to services, at least from 12 months, has resulted, with clear evidence in Sweden of a narrowing of inequalities in access as well. Increased government funding has also supported increased participation in New Zealand. Brazil has set targets for access, and attendance has risen, although the level of services for children under 3 lags behind that for services for the over $3 \mathrm{~s}$, as is also the case in Jamaica. By contrast, the difference between under and over $3 s$ - in terms of level and quality of provision - is much less in Sweden, Slovenia and New Zealand.

\section{No evidence of 'schoolification' except in Sweden}

Except in Sweden, there is no clear evidence that integration within education has resulted in 'schoolification', while in Jamaica, the reform is reported to have eased the grip of compulsory education on early years services. In Ghent, the risk was averted by keeping 'day care' centres and infant schools separate, while working to develop a shared pedagogical approach(Peeters \& Vandenbroeck, in press). In some respects, the consequences of integration within education have been greatest in New Zealand. Overall, there are few negative comments on education-based integration and there is widespread support for the reforms with no significant body of opinion arguing for going back to split systems and/or welfare system involvement. 


\section{Countries that have not integrated ECCE: another perspective}

\section{Which countries were examined}

While integration within education is a growing trend, many countries maintain split systems for governing ECCE. It is therefore important to understand why an integrated system may not seem either an obvious or even possible direction to take. For this reason, this study looked at three countries Belgium Flanders, France and Hungary - that have retained split ECCE systems. All cases represent a particular kind of split system, i.e. a split based on the age of children and with an education sector dominating the ECCE system, offering three years of full-time school or kindergarten to nearly all children over 3 years old. Some general criticisms of split systems have been confirmed in the cases studied, including inequalities between the childcare and early education sectors and lack of continuity from the child's perspective during the transition from one sector to the other.

\section{Why these countries do not integrate their services}

A clear feature in these countries is that there is little or no demand for integration. One reason is the separate culture and tradition of the childcare and early education sectors; this is particularly strong in Belgium Flanders and France. Another is fear of the childcare sector being overwhelmed by, and lost in, education. There are also economic implications, in particular, the costs of upgrading the childcare workforce and other investments in services for children under 3.

Although no apparent steps are being taken to mend the split system, efforts to improve the level and quality of ECCE provision are evident in all three cases. In sum, improved provision is possible without waiting upon major structural reform (Peeters \& Vandenbroeck, in press). Hungary is the country that seems more likely to introduce change - not so much for pedagogical or equity reasons, but because it needs to provide more places in nurseries for children under 3. While tensions exist between sectors and their workforces, Hungary does have two potential advantages if it enters into reform: a common local administration of services with a common funding system in place; and an integrative concept of nevelés, ${ }^{v}$ which provides a common approach and perspective for both nurseries and kindergartens.

\section{Conclusions}

The process of integration is not inevitable but presents many advantages

The overall conclusion must be that the integration of split systems of care and early education is not inevitable. In certain circumstances - particularly in very low income countries - good reasons can be found to continue a health/well-being approach to children 0-3 years and their families, hoping that the opportunity for cognitive stimulation and language development in this period will not be neglected. In industrialised countries, the advantages of integrating all early childhood services within education are more obvious: for children, there is greater continuity and fewer transitions in an integrated system, with under education - more highly trained staff and a greater focus on learning and meaning-making; for parents, there is also the promise within education of more highly subsidised services, universal access and, if long-day services become the rule, of greater access to the labour market.

Another conclusion is that ECCE services can be integrated successfully within a number of policy domains, as long as young children are an important focus of the ministry in charge. However, if the benefits sought from an integrated system include (1) universal entitlement, (2) affordable access, (3) a unified and well educated workforce, (4) enhancing learning for all ages, and (5) smoother transitions for young children, then the education sector is more likely to deliver such benefits, as exemplified by the 
cases studied. Finland, with services integrated in welfare, also delivers these benefits. But Finland (like Denmark) is an example of a Nordic welfare system that shares a number of key principles with education, such as universal access and the importance of learning. Welfare systems in other countries do not generally do so, making them less suitable locations for an integrated ECCE.

This study has shown the benefits that are likely to be produced by the integration of childcare within education. It allows a society to rethink the purpose, provision and practice of ECCE across all age groups, including children both under and over 3 years. It can also provide an opportunity to rethink the meaning of education - should the meaning of education be opened up to accommodate 'childcare' as part of a coherent education system. Integration can change the perceptions of ECCE among the workforce, parents and the wider public, including greater recognition of its pedagogical value. Integration can provide a higher valuation given to staff working in ECCE; the creation of a stronger ECCE system that enjoys parity with and can influence compulsory education; greater coherence in policy; the reduction or elimination of inequalities between services for children under and over 3 years; and increased resourcing for ECCE through merging administrations and eliminating duplication.

\section{But there are several caveats}

\section{The concepts and processes of integration are complex}

The issue is not a simple binary choice of 'split' versus 'integrated'. 'Integrated' systems can vary in depth (i.e. the extent of conceptual and structural integration) and location (e.g. in welfare or education). It is therefore better understood not as a categorical established state but as a continuum, ranging from minimal to full integration.

\section{Some contexts need primarily infant health (pre- and} post-natal care) and parenting supports

This is most obviously true of developing countries, but it applies also to excluded populations and neighbourhoods in the richer countries where infant mortality may be high and primary health and social services difficult of access. In such situations, if financing trade-offs are to be made, it may well be in the interests of families with young children to receive first of all health and social services in the critical first years, with stimulation and early education provided through community channels. However, when countries are well developed with sound child health and welfare systems in place, there is little reason other than traditional ministry responsibilities - to prevent the integration of care and early education services. Long-day programmes with play and challenging project work can be conducted by trained educators during the morning, followed by less intensive activities in the afternoon. For such countries, an appropriate mix of services, of staff and curriculum can be arrived at after piloting in selected areas.

\section{The process of integration can take place in different ways}

The process of integration in education can take place in different ways. In some cases, such as New Zealand, but also Brazil and Jamaica, the start of the integration process and locating all ECCE services in education have occurred at the same time; in other cases, such as Sweden, services have first been fully integrated into another system (typically welfare), then at a later date transferred to education.

\section{Integration requires a re-thinking of the system}

Integration is not an inevitability but a possibility, depending on the interplay of barriers to change and drivers for change. Integration can take place at different levels but is most effective when all levels are committed. It requires re-thinking as well as reforming structures, such as funding, regulation and 
workforce.

\section{Deep integration requires careful thought about the conditions needed}

Integration is not a magic solution but a reform that can be both beneficial and dangerous. Depending on why and how integration is implemented, the reform may deliver the benefits listed on page 40 above. The reform could also bring some or all of the following drawbacks: 'schoolification', although this is a risk under any system whether split or integrated; poorer relations with other services (e.g. health, protection); and increased costs, needed to undertake major structural changes, e.g. to create a better qualified and paid workforce, to increase access and participation, to lower fee income, to introduce a new curricula.

\section{A major question: can education think broadly enough?}

Simply moving administrative responsibility for ECCE into education is not enough. If integration into education is considered, attention has to be paid to the subsequent processes, e.g. the relationship with other services and policy fields. Even more important is the need to re-think concepts such as the meaning and purposes of education and the relationship between pre-school and school. Questions such as whether the education sector can provide a supportive environment to family day care (a form of individual ECCE provision where an individual carer provides for a small number of children in her own home) depends on how education is understood and the capacity of education to think more broadly.

\section{Lessons on how to integrate within education}

In the course of the study, some broad lessons were identified to facilitate integration within education:

- Leadership, alliances with the major stakeholders and advocacy based on strong arguments, are needed in order to get reform moving in the first place.

- Second, to get change deep into the system, there is a need for action at all levels of government and the consensual formulation of strong and integrative concepts on which to build substantive reform.

- Third, to get change into actual practice a strategy is necessary including attention to resources and materials, support workers and training, and time, not least to reflect on practice.

At the international level, two strong lessons emerge:

- That we can learn from and with each other. Countries interested in changing from a split system can gain support from developing dialogue with other countries that have already moved to integrated systems.

- That more and deeper studies of integration are required across a wide range of countries, including low income countries. It would also be of interest to include in these studies countries, such as Australia, Korea and Japan, that not only practise split systems but have also parallel split systems for children from 3 or 4 years up to school age.

\section{References}

Carr, M. (2001). Learning Stories. London: PCP.

Dahlberg, G., \& Lenz Taguchi, H. (1994). Förskola och skola - om toå skilda traditioner och om visionen om en mötesplats [Pre-school and school - two different traditions and the vision of a meeting place]. Stockholm: HLS Förlag.

European Commission Childcare Network. (1996). Quality targets in services for young children. Brussels: European Commission Equal Opportunities Unit.

Hadadd, L. (2002). An integrated approach to early childhood education and care. (Early Childhood and Family Policy Series No. 3). Paris: UNESCO.

Jones, J., Brown, A., \& Brown, J. (in press). Caring and 
learning together: A case study of Jamaica. Paris: UNESCO.

Lenz Taguchi, H., \& Munkammar, I. (2003). Consolidating governmental early childhood education and care services under the Ministry of Education and Science: a Swedish case study. Paris: UNESCO.

Marjanovič Umek, L., \& Fekonja, U. (in press). Caring and learning together: A case study of Slovenia. Paris: UNESCO.

Meade, A., \& Podmore, V. (2002). Early childhood education policy co-ordination under the auspices of the Department/Ministry of Education: A case study on New Zealand. Paris: UNESCO.

Peeters, J., \& Vandenbroeck, M. (in press). Caring and learning together: A case study of Ghent of Belgium Flemish Community. Paris: UNESCO.

Rayna, S. (2003). Implementation of the integrated early childhood policy in Senegal. (UNESCO Early Childhood and Family Policy Series No. 2). Paris: UNESCO.

Ranya, S. (2007). Early childhood education in France. In R. S. New \& M. Cochran (Eds.), Early childhood education: An international encyclopedia. (Vol. 4, pp. 1063-1068). Westport, CT: Praeger.

Recende Nunes, M. F., Corsino, P., \& Didonet, V. (in press). Caring and learning together: A case study of Brazil. Paris: UNESCO

Rinaldi, C. (2006). In dialogue with Reggio Emilia: Listening, researching and learning. London: Routledge.

UNESCO. (2006). Education for all global monitoring report. Strong foundations: Early childhood care and education. Paris: Author.

UNESCO. (2010). Caring and Learning Together. Paris: Author.

United Nations. (1948). Universal declaration of human rights, art (No.23). Geneva: UNCHR.

United Nations Development Programme. (2009). Human development report. New York: UNDP.

\section{NOTES}

$\mathrm{i}$ The article is based on Caring and Learning Together (UNESCO, 2010), http://www.unesco.org/en/earlychildhood/ publications.

ii This process is often referred to as 'schoolification' or the downward pressure of primary school approaches (classroom organisation, curriculum, teaching methods, child:staff ratios and conceptions of childhood) on early childhood pedagogy.

iii Reports were commissioned to obtain information about the experiences of adopting and implementing the decision to integrate ECCE within education in Brazil, Jamaica, Ghent (Belgium Flanders), New Zealand, Slovenia and Sweden.

iv The term 'schoolification' denotes the downward pressure of primary school approaches (classroom organisation, curriculum, teaching methods, child:staff ratios and conceptions of childhood) on early childhood pedagogy.

v The term 'nevelés' has a central role in early childhood work in Hungary. It does not have an exact English equivalent, the closest translation being 'upbringing'. It is a holistic concept, including not just care and education (considered as very closely related, if not inseparable), but also health, behaviour and social skills - everything needed in life. It has, therefore, much in common with the concept of 'social pedagogy' (as used, for example, in Denmark or Germany) or 'education in its broadest sense'. 